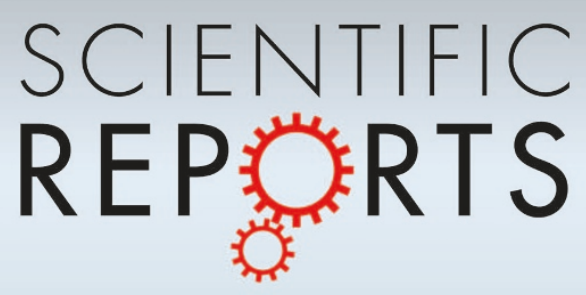

OPEN

SUBJECT AREAS:

STRUCTURAL PROPERTIES

MECHANICAL PROPERTIES

Received

25 April 2014

Accepted

21 July 2014

Published

15 September 2014

Correspondence and requests for materials should be addressed to

A.J. (anne.joulain@ univ-poitiers.fr)

\section{Evidence of dislocation cross-slip in MAX phase deformed at high temperature}

\author{
Antoine Guitton, Anne Joulain, Ludovic Thilly \& Christophe Tromas
}

Pprime Institute - Department of Physics and Mechanics of Materials, UPR 3346, CNRS - University of Poitiers - ISAE-ENSMA, SP2MI, Boulevard Marie et Pierre Curie, BP 30179, 86962 Futuroscope Chasseneuil Cedex, France.

$\mathrm{Ti}_{2} \mathrm{AlN}$ nanolayered ternary alloy has been plastically deformed under confining pressure at $900^{\circ} \mathrm{C}$. The dislocation configurations of the deformed material have been analyzed by transmission electron microscopy. The results show a drastic evolution compared to the dislocation configurations observed in the $\mathrm{Ti}_{2} \mathrm{AlN}$ samples deformed at room temperature. In particular, they evidence out-of-basal-plane dislocations and interactions. Moreover numerous cross-slip events from basal plane to prismatic or pyramidal planes are observed. These original results are discussed in the context of the Brittle-to-Ductile Transition of the nanolayered ternary alloys.

$\mathrm{T}$

i $i_{2} A l N$ belongs to the 211 family of $M_{n+1} A X_{n}$ phases, where $n=1$ to $3, M$ is a transition metal, $A$ is an Agroup element and $\mathrm{X}$ is nitrogen or carbon ${ }^{1}$. These ternary hexagonal nanolayered compounds combine properties of both ceramics (refractory, high stiffness, low density, low ductility at room temperature) and metals (high thermal and electric conductivity, thermal shock resistance, low hardness, mechanical resistance) which make them attractive for a wide range of potential applications. However, their elementary deformation mechanisms and the exact role of microstructural defects are not fully understood yet.

Although there is little literature on dislocations in MAX phases, it is well established that deformation at room temperature involves dislocation movement; these dislocations are $a$-type basal dislocations $(\mathbf{b}=$ $1 / 3<11-20>$ ) and glide in the basal plane $e^{2,3}$ forming large dislocation pile-ups and walls ${ }^{2,4-7}$. The latter may interact to form pairs of low angle tilt boundaries (kink bands) leading to strong local crystal rotation associated with delamination in basal planes ${ }^{8}$. Out-of-basal-plane dislocations have been observed by Transmission Electron Microscopy (TEM), in as-grown $\mathrm{Ti}_{4} \mathrm{AlN}_{3}{ }^{9}$ and by Atomic Force Microscopy (AFM) in nano-indented $\mathrm{Ti}_{3} \mathrm{SnC}_{2}{ }^{10}$ but they do not play a key role in the plastic deformation at Room Temperature (RT) in standard deformation conditions. On the contrary, numerous dislocation dipoles, alignments, nodes have been observed in RT-deformed $\mathrm{Ti}_{2} \mathrm{AlN}^{3}$. Such dislocation reactions may result in the formation of dislocation cells as observed in $\mathrm{Ti}_{2} \mathrm{AlN}^{3}$. The presence of dislocation interactions and networks has to be considered in the comprehension of the deformation mechanisms. Moreover dislocations were also observed to align along specific directions leading to segments with screw, $30^{\circ}, 60^{\circ}$ or edge character, indicative of an elevated lattice friction ${ }^{3}$.

Importantly, MAX phases exhibit a Brittle-to-Ductile Transition (BDT) between $800^{\circ} \mathrm{C}$ and $1100^{\circ} \mathrm{C}^{1,8,11}$. In many materials such BDT is attributed to an increase of the available glide systems ${ }^{12,13}$. Based on the drop of

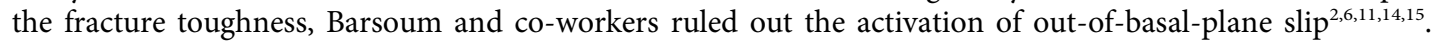
Consequently, they made the assumption that BDT is due to a temperature dependent grain boundary decohesion stress and/or delamination stress ${ }^{6}$. However Li et al. recalled that the activation of out-ofbasal-plane slip systems could not be excluded as long as no observation by TEM of deformed samples had been reported ${ }^{14}$.

The general objective of our work is to study the evolution of the deformation microstructure with the temperature. Dislocation microstructure in polycrystalline $\mathrm{Ti}_{2} \mathrm{AlN}$ deformed at room temperature has been analyzed in a previous paper ${ }^{3}$ from compression tests performed under gaseous (Ar) confining pressure. Indeed this confining pressure impedes crack opening due to the brittleness of the material. In this paper, we present an original and detailed TEM dislocation analysis of $\mathrm{Ti}_{2} \mathrm{AlN}$ deformed at $900^{\circ} \mathrm{C}$ - that is above the $\mathrm{BDT}$ temperature - under the same gaseous confining condition $(\approx 350 \mathrm{MPa})$. Burgers vectors are determined from extinction conditions using the weak beam technique, and dislocation lines are obtained from observations along different orientations. In order to give elements to the comprehension of the BDT, the dislocation configurations are compared to the ones observed at RT. 


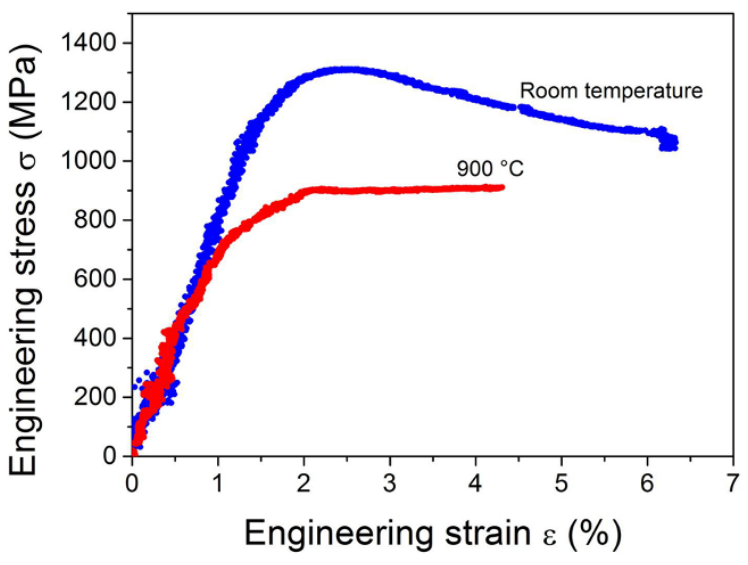

Figure 1 Comparison of stress-strain curves obtained under gaseous confining pressure on $\mathrm{Ti}_{2} \mathrm{AlN}$ at room temperature and $900^{\circ} \mathrm{C}$.

\section{Results}

Figure 1 shows the stress-strain curves of $\mathrm{Ti}_{2} \mathrm{AlN}$ recorded at $\mathrm{RT}$ and at $900^{\circ} \mathrm{C}$ and obtained under the same gaseous confining pressure of $\approx 350 \mathrm{MPa}$, the RT curve being extracted from the reference 3 . In such experimental conditions, the confining pressure hinders crack propagation but does not modify the dislocation behavior ${ }^{16}$. In these conditions, significant plastic strain has been reached: $\varepsilon_{\mathrm{P}}=5 \%$ at RT and $\varepsilon_{\mathrm{P}}=3.5 \%$ at $900^{\circ} \mathrm{C}$ after return to room pressure. Noteworthy, the tests have been arbitrarily stopped at these strains, without rupture for both samples, since steady-state was reached. Both curves exhibit a linear elastic regime followed by a plastic regime. The RTcase is characterized by a stress peak $\sigma_{\mathrm{p}}$ followed by a softening regime and the start of a zero hardening regime. The hightemperature curve does not show any clear stress peak but rather a constant hardening regime followed by a long zero hardening regime. In addition, the maximum stress is lower at $900^{\circ} \mathrm{C}(900 \mathrm{MPa})$ than at RT $\left(\sigma_{\mathrm{p}}=1300 \mathrm{MPa}\right)$, while the yield strength (defined as stress at $0.2 \%$ strain) is lower at $900^{\circ} \mathrm{C}(750 \mathrm{MPa})$ than at RT $(1100 \mathrm{MPa})$.

Figure 2 shows typical dislocation microstructures of the samples deformed respectively at RT and at $900^{\circ} \mathrm{C}$ and gives evidence of the drastic evolution of the dislocation configurations between both samples. On figure 2.a (RT case), straight, segmented dislocations lying in the (0001) plane are observed, similar to the configuration analyzed in reference 3 . Figure $2 . \mathrm{b}\left(900^{\circ} \mathrm{C}\right.$ case $)$ exhibits curved dislocations with segments obviously lying out-of-basal plane (localized by black arrows in Figure 2.b). Two characteristic configurations of the $900^{\circ} \mathrm{C}$ deformed sample are studied in detail below. The first configuration, labeled I in the following is presented in Figure 3, the second one, labeled II, is presented in Figure 4.

Three electron beams along [-1100], [-12-10] and [-12-1-1] directions were used to observe the configurations to be discussed. These electron beams provide five diffraction vectors for the weak beam analysis of both configurations: $\mathbf{g}_{1}=11-20, \mathbf{g}_{2}=10-10, \mathbf{g}_{3}=01-13$, $\mathbf{g}_{4}=-1103$ and $\mathbf{g}_{5}=000 \delta$.

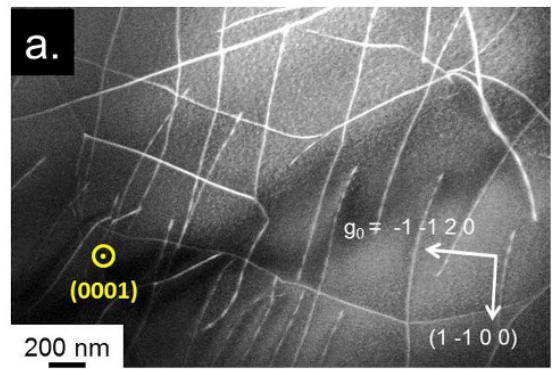

Figure 3 shows micrographs of configuration I, obtained with $\mathbf{g}_{1}$, $\mathrm{g}_{2}$ and $\mathrm{g}_{4}$. Due to the complexity of this configuration, we are focusing here on two segments, 1 and 2 (see schematic in Figure 3-d). Table 1 reports the observed contrasts for both segments using $\mathbf{g}_{1}, \mathbf{g}_{2}$, $\mathbf{g}_{3}, \mathrm{~g}_{4}$ and $\mathbf{g}_{5}$. Segments 1 and 2 are out of contrast with the diffraction vectors $\mathbf{g}_{3}$ and $\mathbf{g}_{5}$, confirming that they belong to the same dislocation. According to these extinction conditions, their Burgers vector is lying in the basal plane (out of contrast with $\mathbf{g}_{5}$ ) and is consistent with $\mathbf{b}_{1}= \pm 1 / 3$ [2-1-10]. The analysis of dislocation lines shows that the segment 1 is lying in (0001) plane and aligned along [2-1-10]. However the segment 2 is clearly parallel to [0001]. Consequently this dislocation is contained in the prismatic plane (0-110). Dislocation nature of the segments $\mathbf{1}$ and $\mathbf{2}$ is screw and edge respectively. The configuration I is the first evidence of dislocation cross-slip from basal dislocation to prismatic plane $\{0-110\}$, as schematized in Figure 3d.

The configuration II is presented in Figure 4. The micrographs are also obtained with $g_{1}, g_{2}, g_{3}, g_{4}$ and $g_{5}$. Here again, due to the complexity of this configuration, we are focusing on specific segments of the configuration, here $1,2,3$ and 4 . The analysis of dislocation contrasts is presented in Table 1.

In the same manner as for configuration I, the segments 1 and 2 belong to the same dislocation since they have the same extinction conditions with $g_{3}$ and $g_{5}$. The segment 1 is parallel to [11-20] and lies in (0001). On the contrary, the segment 2 is out of the basal plane. Available observation conditions impeded to define precisely its line direction; nevertheless one can assert that both segments 1 and 2 are contained in a pyramidal plane. Concerning Burgers vector, the extinction conditions with $\mathbf{g}_{3}$ and $\mathbf{g}_{5}$ reveal that it is consistent with $\mathbf{b}_{1}=\mathbf{b}_{2}= \pm 1 / 3$ [2-1-10]. Noteworthy, segment $\mathbf{1}$ (lying in the basal plane) is not a screw dislocation, the angle between its dislocation line and its Burgers vector being equal to $60^{\circ}$.

The segment 3 of configuration II is out of the basal plane. Again, its line could not be determined. This segment does not exhibit the same extinction conditions as those of segments $\mathbf{1}$ and 2 , confirming that segment 3 has a different Burgers vector from the dislocation formed by 1 and 2 , as expected from the dislocation nodes rule $\mathbf{b}_{1}=$ $\mathbf{b}_{2}=\mathbf{b}_{3}+\mathbf{b}_{3}{ }^{\prime}$ (the segment $\mathbf{3}^{\prime}$ is shown on Figure 4). This observation reveals an out-of-basal-plane interaction as localized by arrows in the micrographs of Figure 4. Moreover the segment 3 is observed to be out of contrast with $g_{4}$ and $g_{5}$. Consequently its Burgers vector is consistent with $\mathbf{b}_{3}=1 / 3$ [11-20].

Concerning the segment 4, Figure 4 shows that, from geometrical considerations, it is lying out of the basal plane and highly curved. It interacts with segment 3 and another dislocation thus forming a node. The details of this interaction could not be determined. Similarly to segments 1 and 2 , segment 4 is out of contrast with $\mathbf{g}_{3}$ and $\mathbf{g}_{5}$. Consequently its Burgers vector is $\mathbf{b}_{4}=1 / 3$ [2-1-10].

\section{Discussion}

TEM observations show that $\mathrm{Ti}_{2} \mathrm{AlN}$ was plastically deformed at $900^{\circ} \mathrm{C}$ through the production and movement of dislocations.

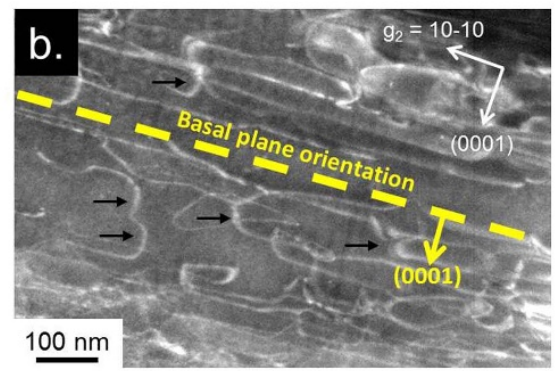

Figure $2 \mid$ Typical dislocation configurations of $\mathrm{Ti}_{2} \mathrm{AlN}$ deformed at room temperature (a) and at $900^{\circ} \mathrm{C}(\mathrm{b})$. In both cases, the basal plane orientation is shown. In (b) black arrows indicate dislocation segments lying out of the basal plane. 

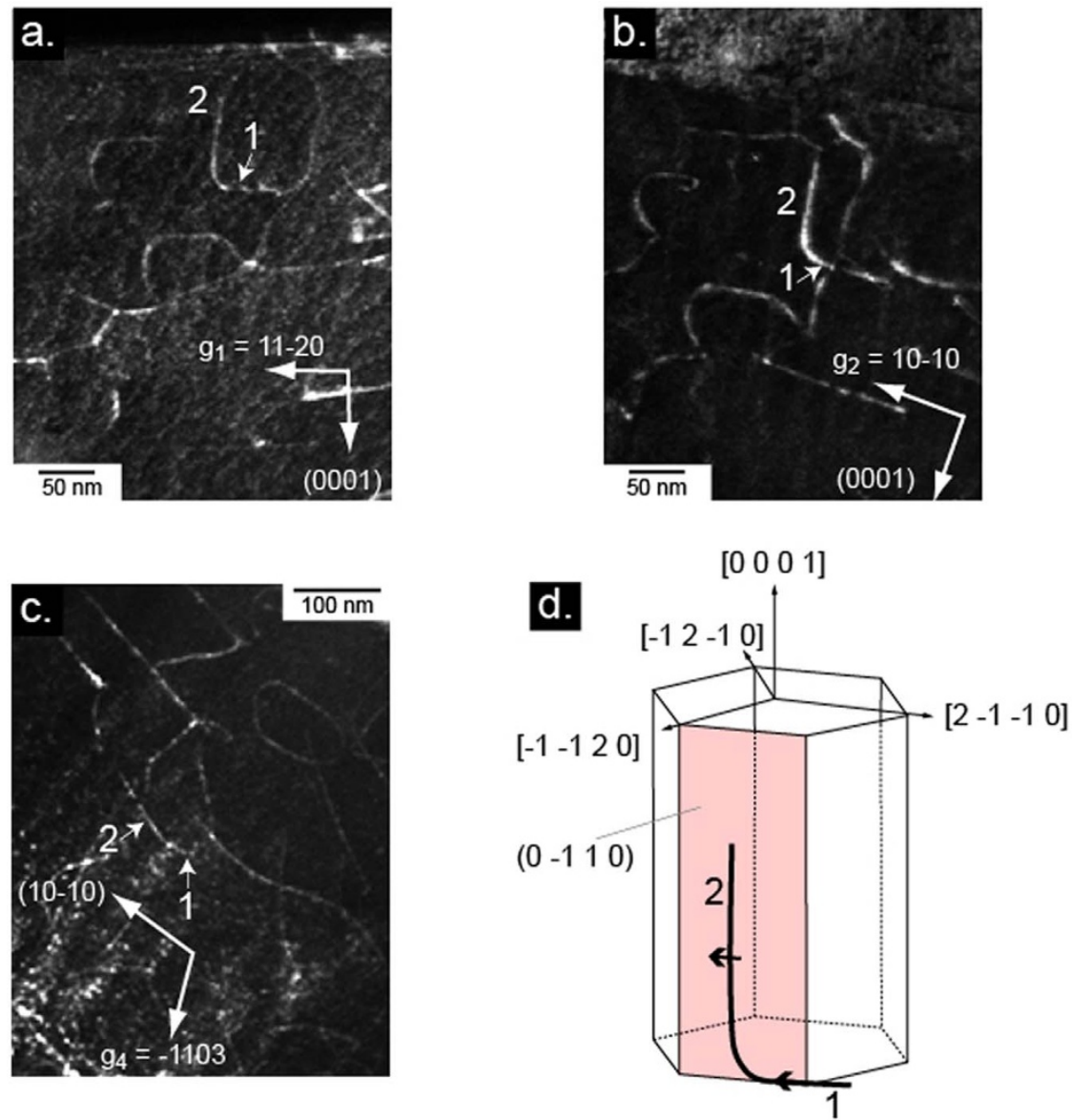

Figure 3 Configuration I. Dark Field images obtained using $g_{1}=11-20$ (a), $g_{2}=10-10$ (b) and $g_{4}=-1103$ (c). (d) 3D schematic representation of the configuration.
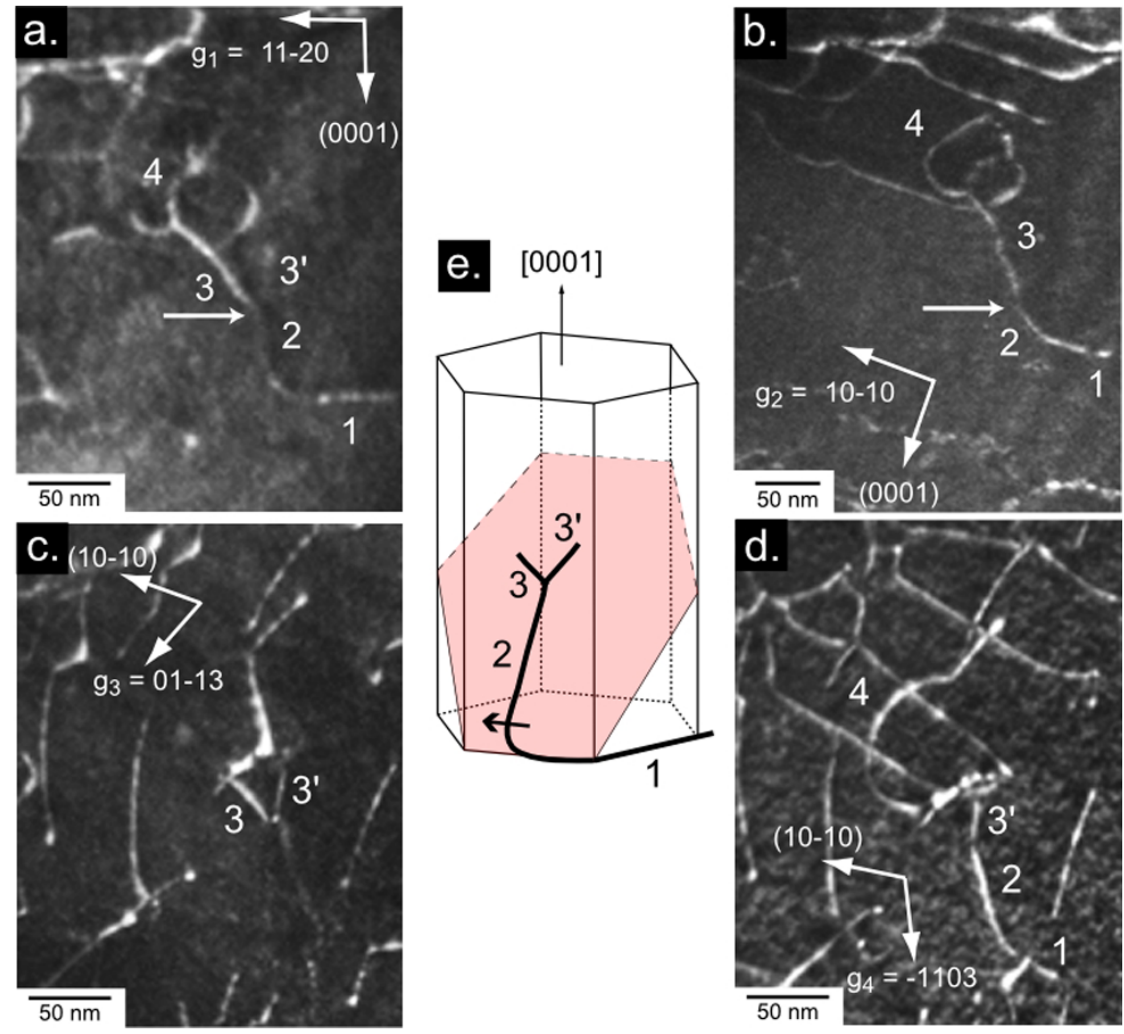

Figure $4 \mid$ Configuration II. Dark Field images obtained using $g_{1}=11-20$ (a), $g_{2}=10-10$ (b), $g_{3}=01-13$ (c) and $g_{4}=-1103$ (d). (e) $3 \mathrm{D}$ schematic representation of the configuration. The arrows localize an out-of-basal-plane interaction. 
Table 1 | Contrasts of the configurations I and II under different diffraction conditions (Figure 3 and Figure 4). $\checkmark$ : in contrast, $\boldsymbol{X}$ : out of contrast, $\ell$ : dislocation line and $\alpha$ : absolute value of the angle between $b$ and $\ell$, o.b.p.: out of basal plane

\begin{tabular}{|c|c|c|c|c|c|c|c|c|c|}
\hline & & $y_{1}=11-20$ & $g_{2}=10-10$ & $g_{3}=01-13$ & $g_{4}=-1103$ & $g_{5}=000 \delta$ & Burgers vector $\boldsymbol{b}$ & Line $\ell$ & $\alpha\left(^{\circ}\right)$ \\
\hline \multirow[t]{2}{*}{ I } & 1 & $\checkmark$ & $\checkmark$ & $x$ & $\checkmark$ & $x$ & $\pm 1 / 3[2-1-10]$ & {$[2-1-10]$} & 0 \\
\hline & 2 & 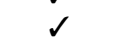 & 1 & $x$ & 1 & $x$ & $\pm 1 / 3[2-1-10]$ & {$[0001]$} & 90 \\
\hline \multirow[t]{5}{*}{ II } & 1 & 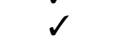 & 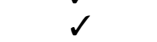 & $x$ & 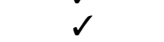 & $x$ & $\pm 1 / 3[2-1-10]$ & {$[11-20]$} & 60 \\
\hline & 2 & $s$ & $s$ & $x$ & $s$ & $x$ & $\pm 1 / 3[2-1-10]$ & o.b.p & $?$ \\
\hline & 3 & $s$ & $s$ & $s$ & $x$ & $x$ & $\pm 1 / 3\left[\begin{array}{ll}1 & 1-20\end{array}\right.$ & o.b.p & ? \\
\hline & $3^{\prime}$ & $\checkmark$ & $x$ & $\checkmark$ & $\checkmark$ & $x$ & $\pm 1 / 3[1-210]$ & o.b.p & $?$ \\
\hline & 4 & 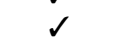 & 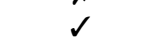 & $x$ & 1 & $x$ & $\pm 1 / 3[2-1-10]$ & o.b.p & ? \\
\hline
\end{tabular}

Comparison between configurations observed in RT- and $900^{\circ} \mathrm{C}-$ deformed samples provides evidence of a radical evolution of dislocation configurations. While at room temperature, dislocations lines are straight and confined to the basal plane, at $900^{\circ} \mathrm{C}$, they present much more complex nature: (1) dislocations lines are curved; (2) they cross-slip from basal plane to $1^{\text {st }}$ order prismatic and pyramidal planes, and (3) they react and form junctions out of the basal plane. All these dislocations are of $a$-type i.e. with a Burgers vector lying in the basal plane, which explains the easiness of cross-slip.

Our study reveals unambiguously, and for the first time in MAX phases, that at high temperature out-of-basal-plane dislocations are not anecdotal events and therefore cross-slip plays a key role in the deformation. This increase of available glide systems at high temperature (basal, prismatic and pyramidal planes) is likely to promote significant ductility at high temperature. In conclusion, these major changes in the plasticity mechanism are expected to play a key role in the appearance of the BDT with temperature notably with respect to the decrease of the yield strength when increasing temperature.

While the high temperature response of MAX phases was supposed to be only based on temperature dependent grain boundary decohesion and/or interplanar delamination stress ${ }^{17}$, the present work provides new elements through the observation of cross slip events. Further experiments would now be performed at intermediate temperatures to correlate precisely the apparition of the BDT with an abrupt or gradual change of plasticity mechanism as in the case of semi-conductor ${ }^{12,13}$.

\section{Methods}

Synthesis procedure. The synthesis procedure for the $\mathrm{Ti}_{2} \mathrm{AlN}$ sample has been described in detail elsewhere ${ }^{3}$. Briefly, titanium (grain size $<149 \mu \mathrm{m}$ ), AlN $(<10 \mu \mathrm{m})$ were mixed in stoichiometric proportions. The mixture was placed into a Hot Isostatic Pressing (HIP) chamber to be heated up to $1450^{\circ} \mathrm{C}$ under a pressure of $80 \mathrm{MPa}$ for 4 hours. Porosity measurements, X-ray diffraction and Scanning Electron Microscopy (SEM) studies revealed that the $\mathrm{Ti}_{2} \mathrm{AlN}$ sample was dense with randomly oriented grains with a typical size of $15 \mu \mathrm{m}$.

Compression test. In order to reach significant plastic strain, uniaxial compression test was performed in the Paterson's apparatus at $900^{\circ} \mathrm{C}$ under an argon confining pressure of $350 \mathrm{MPa}$ at a strain rate equal to $5 \cdot 10^{-5} \mathrm{~s}^{-1}$. Deformation under confining pressure requires samples cut into parallelepipeds with typical size $3 \times 3 \times$ $7 \mathrm{~mm}^{3}$. All faces were carefully mechanically polished and inserted into fully annealed aluminium or iron cylinders to fit into the deformation assembly of the compression apparatus. After deformation, the samples were removed from $\mathrm{Al}$ or $\mathrm{Fe}$ jackets for TEM analysis.

Transmission electron microscopy. The thin foil for TEM observations was cut at $45^{\circ}$ from the compression axis and prepared by slow mechanical polishing and dimpling down to a few microns. Subsequently the thin foil was glued on molybdenum grid and thinned down to electron transparency in a Precision Ion Polishing System (PIPS from Gatan). TEM observations were performed on a Phillips CM20 microscope operating at $200 \mathrm{kV}$.

1. Barsoum, M. \& El-Raghy, T. The MAX phases: unique new carbide and nitride materials. Am. Sci. 89, 334-345 (2001).

2. Barsoum, M. \& Radovic, M. Mechanical properties of the MAX phases. Enc. Mater. Sci. Techno. 16, 1-16 (2004).
3. Guitton, A., Joulain, A., Thilly, L. \& Tromas, C. Dislocation analysis of $\mathrm{Ti}_{2} \mathrm{AlN}$ deformed at room temperature under confining pressure. Philos. Mag. 92, 4536-4546 (2012).

4. Farber, L., Levin, I. \& Barsoum, M. High-resolution transmission electron microscopy study of a low-angle boundary in plastically deformed $\mathrm{Ti}_{3} \mathrm{SiC}_{2}$. Philos. Mag. 79, 163-170 (1999).

5. Kooi, B., Poppen, R., Carvalho, N., Hosson, J. \& Barsoum, M. Ti ${ }_{3} \mathrm{SiC}_{2}$ : A damage tolerant ceramic studied with nanoindentations and transmission electron microscopy. Acta Mater. 51, 2859-2872 (2003).

6. Barsoum, M. \& Radovic, M. Elastic and mechanical properties of the MAX phases. Annu. Rev. Mater. Res. 41, 195-227 (2011).

7. Barsoum, M., Zhen, T., Kalidindi, S., Radovic, M. \& Murugaiah, A. Fully reversible, dislocation-based $\mathrm{Ti}_{3} \mathrm{SiC}_{2}$ to $1 \mathrm{GPa}$. Nature Mater. 2, 107-111 (2003).

8. Barsoum, M., Farber, L. \& El-Raghy, T. Dislocations, kink bands, and roomtemperature plasticity of $\mathrm{Ti}_{3} \mathrm{SiC}_{2}$. Metall. Mater. Trans. A. 30, 1727-1738 (1999).

9. Joulain, A., Thilly, L. \& Rabier, J. Revisiting the defect structure of MAX phases: the case of $\mathrm{Ti}_{4} \mathrm{AlN}_{3}$. Philos. Mag. 88, 1307-1320 (2008).

10. Tromas, C., Villechaise, P., Gauthier-Brunet, V. \& Dubois, S. Slip line analysis around nanoindentation imprints in $\mathrm{Ti}_{3} \mathrm{SnC}_{2}$ : a new insight into plasticity of MAX-phase materials. Philos. Mag. 91, 1265-1275 (2010).

11. Zhang, Z. F. \& Sun, Z. M. Shear fracture behavior of $\mathrm{Ti}_{3} \mathrm{SiC}_{2}$ induced by compression at temperatures below $1000^{\circ}$ C. Mater. Sc. Eng. A. 408, 64-71 (2005).

12. Kedjar, B., Thilly, L., Demenet, J.-L. \& Rabier, J. Plasticity of indium antimonide between -176 and $400^{\circ} \mathrm{C}$ under hydrostatic pressure. Part I: Macroscopic aspects of the deformation. Acta. Mat. 58, 1426-1440 (2010).

13. Kedjar, B., Thilly, L., Demenet, J.-L. \& Rabier, J. Plasticity of indium antimonide between $-176^{\circ} \mathrm{C}$ and $400^{\circ} \mathrm{C}$ under hydrostatic pressure. Part II: Microscopic aspects of the deformation. Acta. Mat. 58, 1418-1425 (2010).

14. Li, J. F., Pan, W., Sato, F. \& Watanabe, R. Mechanical properties of polycrystalline $\mathrm{Ti}_{3} \mathrm{SiC}_{2}$ at ambient and elevated temperatures. Acta Mater. 49, 937-945 (2001).

15. Wan, D. T., Meng, F. L., Zhou, Y. C., Bao, Y. W. \& Chen, J. X. Effect of grain size, notch width, and testing temperature on the fracture toughness of $\mathrm{Ti}_{3} \mathrm{Si}(\mathrm{Al}) \mathrm{C}_{2}$ and $\mathrm{Ti}_{3} \mathrm{AlC}_{2}$ using the chevron-notched beam (CNB) method. Euro. Ceram. Soc. 28, 663-669 (2008).

16. Pizzagalli, L., Demenet, J. L. \& Rabier, J. Theoretical study of pressure effect on the dislocation core properties in semiconductors. Phys. Rev. B. 79, 045203, 1-7 (2009).

17. Barsoum, M. "Mechanical Properties: High Temperature" in MAX Phases: Properties of Machinable Ternary Carbides and Nitrides, ( $1^{\text {st }}$ Edition p363-397). Germany: Wiley-VCH; (2013).

\section{Author contributions}

All the TEM observations were performed by A.G. and A.J. A.G. wrote the main manuscript text. L.T. and A.G. performed the mechanical deformations. C.T. and A.G. prepared Figures 3 and 4 . All the authors reviewed the manuscript.

\section{Additional information}

Competing financial interests: The authors declare no competing financial interests.

How to cite this article: Guitton, A., Joulain, A., Thilly, L. \& Tromas, C. Evidence of dislocation cross-slip in MAX phase deformed at high temperature. Sci. Rep. 4, 6358; DOI:10.1038/srep06358 (2014).

This work is licensed under a Creative Commons Attribution-NonCommercialNoDerivs 4.0 International License. The images or other third party material in this article are included in the article's Creative Commons license, unless indicated otherwise in the credit line; if the material is not included under the Creative Commons license, users will need to obtain permission from the license holder in order to reproduce the material. To view a copy of this license, visit http:// creativecommons.org/licenses/by-nc-nd/4.0/ 